\title{
Políticas culturales disputadas: tensiones y desafíos de la cultura en contexto pandémico en Rosario, Argentina
}

\author{
Disputed cultural policies: cultural tensions and challenges in the \\ context of the pandemic in Rosario, Argentina
}

\section{Laura Cardini}

Universidad Nacional de Rosario, Rosario, Argentina

auracardiniaconicet.gov.ar.

https://orcid.org/0000-0001-9807-075X

\section{Resumen}

Este artículo aborda la cultura como objeto de la política pública en la ciudad de Rosario, provincia de Santa Fe, Argentina. En medio de los cambios políticos producto de los resultados eleccionarios de finales del 2019, analizamos la situación del campo cultural público y las transformaciones provocadas por la pandemia Covid-19. Observamos de qué modo las políticas locales son capaces (o no) de responder a tales procesos, a través del análisis de acontecimientos que repercutieron públicamente desde finales del 2019, 2020 y los inicios del 2021. Con perspectiva socioantropológica basada en entrevistas a trabajadoras/es culturales y relevamiento periodístico, registramos algunas de las controversias suscitadas en y desde el sector cultural, en tanto oportunidades para observar el escenario adverso, contradictorio y desigual de las políticas culturales en un contexto específico, que desembocó en el colapso de la gestión cultural y devino en modificaciones en el gabinete municipal.

Palabras clave: Políticas Públicas, Trabajo cultural, Pandemia, Conocimiento socioantropológico.

\begin{abstract}
This article addresses culture as an object of public policy in the city of Rosario, Santa Fe province, Argentina. In the midst of the political changes resulting from the the political elections by the end of 2019, we analyze the situation of the public cultural field and the transformations caused by the Covid-19 pandemic. We observe how local policies are capable (or not) of responding to such processes, through the analysis of events that had a public impact since the end of 2019, during 2002, and at the beginning of 2021. Within a socio-anthropological perspective based on interviews conducted with cultural workers and reviewing journalistic material, we review some of the controversies raised in and from the cultural sector, as opportunities to observe the adverse, contradictory, and unequal scenario of cultural policies in a specific context, which led to the collapse of cultural management and provoked in modifications in the municipal cabinet.
\end{abstract}

Keywords: Public policies, Cultural work, Pandemic, Socioanthropological knowledge. 


\section{Introducción}

La investigación que da cuerpo al presente artículo se enmarca en los estudios que desarrollamos en el Consejo Nacional de Investigaciones Científicas (CONICET) y en la Universidad Nacional de Rosario (UNR) y parten de una perspectiva socioantropológica para abordar las políticas culturales en el contexto argentino, específicamente en la ciudad de Rosario, provincia de Santa Fe, en la región centro de la Argentina. Ubicada en la zona sur de dicha provincia, la ciudad tiene un total de un millón de habitantes, representa la tercera parte de la población de la misma y ha ocupado históricamente un lugar destacado a nivel económico y productivo.

En un contexto de cambios políticos y de rumbos en las políticas públicas en todos los niveles del Estado - por los resultados eleccionarios de 2019 en Argentina'-, con apenas unos meses de nuevos mandatos, se sumó la pandemia provocada por el coronavirus. Las medidas en materia epidemiológica se iniciaron el 20 de marzo de 2020 mediante el Aislamiento Social Preventivo y Obligatorio (ASPO) que confinó a la población en sus hogares (Decreto Nacional 297/2020 y prórrogas). Dicha disposición se implementó junto a medidas estatales tendientes a proporcionar información, prevención y contención del contagio del virus. Con diversos anuncios, medidas y normativas, se alternaron el aislamiento y el distanciamiento social, con la progresiva apertura de actividades y espacios. A nivel nacional, la situación respecto de las consecuencias de la propagación del virus fue variable según las regiones respecto de índices de contagios y de muertes. En la provincia de Santa Fe, el mes de octubre de 2020 constituyó el pico máximo en la expansión del Covid-19.

Hasta la llegada de la pandemia, nuestro trabajo de campo, que incluía entrevistas a funcionarias/ os y trabajadoras/es de las áreas intervinientes y observaciones, era central. Sin embargo, las condiciones de aislamiento y distanciamiento social condujeron a centrarnos en ciertos acontecimientos que tuvieron como protagonista al sector cultural mediante repercusiones publicadas en los medios masivos de comunicación locales ${ }^{2}$. Este acento teórico-metodológico respondió a las transformaciones provocadas por las medidas implementadas debido a la pandemia no sólo so- bre el campo cultural analizado, sino también en nuestras propias condiciones de trabajo socioantropológico, limitado en el acceso presencial a los espacios laborales cotidianos (Boletín Oficial de la República Argentina, 2021)³.

El proceso iniciado a finales de 2019 con el cambio de gobierno y el 2020 con la propagación de la pandemia Covid-19, impulsó a interrogarnos acerca de las transformaciones experimentadas por el campo cultural en torno a: ¿Qué procesos cobraron visibilidad respecto de la situación del sector cultural al interior del Estado y de las organizaciones artísticas culturales, que se vinculan a las políticas públicas municipales producto de la crisis provocada por la pandemia? ¿Qué aspectos de las demandas del sector cultural se detonaron a partir de las medidas asociadas a la pandemia? Estas demandas, ¿estaban presentes con anterioridad a este proceso transnacional? Para aproximarnos a las respuestas recorremos ciertos sucesos publicados en la prensa y en portales de la ciudad, que se dieron a finales de 2019, el transcurso del año 2020 hasta los primeros meses del 2021: asunción de autoridades de área y discursos de la nueva gestión; demandas y manifestaciones de sectores artístico-culturales y de agrupaciones independientes; renuncias de integrantes de dependencias estatales y cambio de autoridad de la cartera cultural. Detenernos en estos acontecimientos permite abordar concepciones, condiciones y desafíos actuales de las políticas culturales en el contexto mencionado4.

\section{Perspectiva teórico-metodológica}

En un sentido amplio, las políticas culturales son un conjunto de intervenciones y de actuaciones que se generan tanto desde los ámbitos estatales, como desde distintos actores, las que, en una dialéctica con las primeras, pueden reforzarlas, rechazarlas y/o confrontarlas IGarcía Canclini, 1987; Achilli, 1998). Desde un punto de vista estructural, consideramos las tendencias y formulaciones de las políticas públicas a nivel general y las trayectorias institucionales de las gestiones culturales particulares; donde se generan fuertes entrelazamientos entre el Estado y los movimientos culturales (Landi, 1987). Tomar en cuenta a los distintos agentes y sujetos involucrados en las políticas culturales, ya sea des- 
de el ámbito estatal, comunitario o privado, implica, además, considerar la agencia, los intereses contradictorios, los posicionamientos desiguales y las disputas de poder entre los diversos actores (Crespo et al., 2015). Y, en un sentido estricto, las políticas culturales constituyen un campo de problemas que se conformó internacionalmente y que impactó a través de la creación de instituciones públicas, organismos y conferencias en la segunda mitad del siglo XX (Bayardo, 2008) ${ }^{\mathbf{5}}$.

Bayardo (2008) propone una periodización de las políticas culturales en términos de "generaciones" a partir de un primer momento signado por la centralidad de las artes y el patrimonio, en tanto corpus consagrado en la edificación de la nación; una segunda instancia que focaliza en las industrias culturales y los medios de comunicación; y una tercera centrada en la imbricación de cultura y desarrollo que propicia una ampliación de la noción de cultura. Estas variaciones registradas a partir del análisis de conferencias y declaratorias internacionales, se sucederán en el transcurso de las distintas décadas y sedimentarán en perspectivas más amplias pero, a la vez, instrumentales de lo cultural como recurso (2008). Y, entre mediados y finales de los 90, las matizaciones devendrán en el papel protagónico de la diversidad cultural y en una especificación más precisa de bienes, servicios e industrias caracterizados como culturales (2008). Para el caso de Argentina y el contexto que analizamos, el impacto de estos hitos que configuran el campo de las políticas culturales a nivel internacional presenta grados variables de resonancia y de correlación con la temporalidad de los procesos atravesados en los planos locales.

Partiendo de los matices teóricos que este campo experimentó tanto a nivel internacional, regional como local, proponemos abordar concepciones y prácticas de la situación del sector cultural de Rosario a través de lo publicado en medios masivos de comunicación locales ${ }^{6}$. Asimismo, consideramos trabajo de campo previo al recorte temporal señalado en la introducción y conversaciones informales con distintos actores y agentes. La lectura del material se realizó teniendo en cuenta aspectos de los contenidos de las notas: a qué actor se privilegiaba la los grupos artísticos-culturales, a los interlocutores autorizados en esta materia); los contextos de significación en los que estos actores eran colocados de manera privilegiada len el contexto de la lucha política, de la precariedad, entre otros) y; el modo de definición de los actores (el Estado, los grupos independientes o autogestivos), que deriva en el problema de los conflictos (en términos de antagonismo, diferencia u oposiciones) (Sunkel, 1987)7, en este caso, respecto de las políticas culturales municipales.

\section{Resultados preliminares}

\subsection{Institucionalización de la cultura en Argentina y en Rosario}

En Argentina los antecedentes de institucionalización de las políticas públicas en materia cultural se remontan a la creación de la Comisión Nacional de Cultura (1933). En los cuarenta se crea la Subsecretaría de Cultura de la Nación (1948) y, en los cincuenta, se suman importantes instituciones, tales como: el Instituto Nacional de Cine y Artes Visuales (INCAA) y el Fondo Nacional de las Artes (FNA). Como apunta Bayardo (2008), la existencia de reparticiones que agrupen a distintas instituciones culturales en un mismo sector de la administración pública se cristaliza en el siglo XX (2008) y en Argentina coexisten dos modelos: uno centralista, en el cual "el Estado interviene activamente en el diseño, financiamiento e implementación de políticas culturales, estableciendo prioridades, planes y programas de acción" (2008, p.18) y otro, en el cual la intervención del Estado es limitada y se orienta a la asignación de fondos hacia el ámbito cultural len referencia a la mencionada Subsecretaría y al FNA).

De modo general, en los ochenta las cuestiones centrales pasan por las libertades y la democratización en todos los ámbitos de la sociedad. Así, en el contexto de reapertura democrática a partir de 1983, se registran procesos de transformación de las estructuras administrativas en todos los ámbitos de las políticas públicas, con la presencia de planes nacionales, en cuya retórica resuenan elementos del campo, tales como la deselitización y democratización cultural. Sin embargo, ello no se tradujo en actividades culturales articuladas. En ese marco, en Argentina se genera un Plan Nacional de Cultura y un Programa de Democratización de la Cultura (Landi, 1987).

En la década de los noventa, se formula el Plan Federal de Cultura (Getino, 1995), contexto en el cual las medidas de corte neoliberal enfatizan en 
la disolución del ámbito estatal y la idea de "gestión cultural" se convierte en hegemónica, sobre todo en los espacios de formación del sector cultural (Elía, 2009; País, 2016; Cerdeira \& Lacarrieu, 2016).

En las primeras décadas del siglo XXI, el énfasis se vuelca a la construcción de igualdades con acento en la perspectiva de los derechos, a través de medidas tendientes a la ampliación de las ciudadanías (Raggio, 2015). En ese marco, se desarrollan procesos de institucionalización del sector cultural a través de la creación de nuevos organismos, funciones y atribuciones de los ya existentes (Cerdeira \& Lacarrieu, 2016), entre los cuales se crea el Ministerio de Cultura de la Nación en 2014 (degradado a Secretaría de Cultura de la Nación durante 2018 y 2019 bajo la órbita de un mismo Ministerio de Educación, Cultura, Ciencia y Tecnología). En 2020, el restituido Ministerio de Cultura reeditó acciones en materia de relevamientos, encuentros y convenios, tomando como eje el retraimiento registrado desde el año 2019 y, sobre todo, con miras a paliar las condiciones agravadas por la pandemia Covid-19.

A nivel de la ciudad de Rosario, la creación de la primera área cultural se remonta a 1937 con una Dirección de Cultura, dependiente de la Secretaría de Gobierno municipal y, entre los años 1960 y 1970 , está presente el accionar del FNA a través de programas y planes que arriban a la ciudad mediante acciones puntuales, en una lógica dirigida a actividades específicas en torno a las artes plásticas, música, teatro, literatura (Catálogo FNA, 1964) y artesanías (La Tribuna, 1978), por mencionar algunas.

A partir de la reapertura democrática, en la década de 1980, comienzan a surgir dependencias en la esfera cultural desde la órbita estatal municipal, tales como la Subsecretaría de Cultura, Turismo y Educación. Desde nuestra perspectiva, se trata de un momento clave de las políticas culturales del municipio y donde las autoridades que encabezan la cartera pertenecen a sectores artísticos de la ciudad con un vasto recorrido y reconocimiento en sus campos. Este período se caracteriza por la restitución del papel del Estado luego del período dictatorial que busca distanciarse del proceso represivo con discursos y acciones en términos de deselitización de la cultura, de pluralismo y de democratización en todas las esferas, pero las mismas no estaban sustentadas en una política en términos de coordinación y planificación.
Avanzado el siglo, ya en la década de 1990, el área pasa a constituirse como Secretaría de Cultura, Turismo y Educación, lo cual implicó disponer de presupuesto propio. Para ese entonces, la dependencia contaba con 29 instituciones entre museos; teatros; bibliotecas; escuelas (Museología, Danzas y Arte Escénico y Música); organismos estables; editorial; servicio educativo; una Dirección de Promoción Cultural, de la cual dependían talleres de participación barrial; centros culturales; casas de Cultura y dependencias del Complejo Astronómico Educativo (Informe Anual 1992-Febrero 1993).

En esos años, el país navegaba la década neoliberal con medidas político-económicas como la flexibilización laboral, la privatización de servicios públicos, la concentración de actividades bancarias y financieras, mientras se producían desempleos masivos, se agudizaba la pobreza y las desigualdades sociales. Pese a las adversidades socioeconómicas del contexto nacional, en Rosario la gestión socialista ${ }^{8}$ impulsó distintos procesos: descentralización político-administrativa en seis distritos y modificaciones en la institucionalidad del sector cultural. En otro nivel de las políticas, para algunas funcionarias, funcionarios y trabajadores, incorporarse al trabajo en el Estado se inscribió en las concepciones de transformación social heredadas de prácticas artísticas y experiencias políticas de las décadas anteriores $(1960,1970)$ y que, a la vez, interpeladas por la coyuntura, eran una vía de salida ante la crisis registrada en esos años?

En simultáneo, y durante la misma década de los noventa, las tendencias hegemónicas internacionales que instalaron lo cultural como recurso para el desarrollo arribaron a la ciudad e incidieron en el primer Plan Estratégico para Rosario (PER, 1998) que, por primera vez, incluye la dimensión cultural como una de sus líneas estratégicas (Cardini, 2018). Mientras se expandían las franjas de esparcimiento y ocio para el consumo y la promoción urbana, en otras zonas de la ciudad se exacerbaron las dificultades en el acceso a los servicios sociales, educativos, de transporte y vivienda. $Y$ en las primeras décadas del siglo XXI, el proceso de ampliación de las dependencias culturales se dio en simultáneo con las innovaciones en la "institucionalidad normativa”, con la nueva denominación del área, que en 2000 se conformó como Secretaría de Cultura y Educación ${ }^{\mathbf{1 0}}$. 
Este proceso de ampliación y complejización del organigrama institucional cultural responde a la composición del campo artístico-cultural de la ciudad caracterizado por sus vinculaciones históricas entre grupos artísticos, organizaciones e instituciones, la apuesta de los gobiernos municipales, principalmente desde el período democrático de convocar a referentes del ámbito artístico al frente de las áreas estatales en cultura. El empuje de y entre colectivos artísticos, organizaciones culturales y movimientos entramó a los agentes claves en y con la estructura burocrática de las áreas estatales.

Actualmente, la ciudad cuenta con 46 dependencias entre las que se incluyen bibliotecas públicas, museos, centros culturales, escuelas de arte, salas y teatros, espacios para la infancia. Además, cuenta con una planta total de 1.026 trabajadores/as pertenecientes a las áreas culturales municipales (Municipalidad de Rosario, 2018).

\subsection{La llegada de la pandemia y las políticas para el sector cultural}

En 2019 el resultado electoral significó cambios en la composición político-partidaria en todos los niveles del Estado: nacional, provincial y municipal. Modificaciones que, para el sector cultural, se expresaron en la reconfiguración de áreas y sus jerarquías, entre otras acciones.

A nivel nacional, la cuenta satélite del Sistema de Información Cultural de la Argentina (SInCA, 2020) informaba que en 2019 se registraba la caída de la actividad cultural respecto de años anteriores. $Y$ en 2020, impulsada por el restituido Ministerio de Cultura Nacional, circuló una Encuesta destinada a engrosar la carga del sistema, que sirvió de primer estado de la cuestión del sector cultural. Desde esa área se asignó una inversión de 66.750 .0000 millones de dólares en medidas destinadas a atender la emergencia sanitaria y se amplió en 133.500 .000 millones de dólares el monto destinado a profundizar y dar continuidad a las políticas implementadas con el Plan Federal de Cultura (Ministerio de Cultura de la Nación, 2020).

La gestión provincial inició un registro de agentes, grupos y espacios culturales cuyos primeros datos arrojaron la cifra de 1.300 proyectos culturales, vin- culados a las postulaciones presentadas en el plan de fomento 2020, medida implementada en el marco de las restricciones impuestas por la pandemia, pensada como "política para la reactivación productiva del sector" (Ministerio de Cultura Provincia de Santa Fe, 2020). El Ministerio de Cultura destinó 2.202.750.000 de dólares americanos para 400 proyectos de todo el territorio provincial. Y la convocatoria, que cerró en el mes de septiembre, contempló distintas líneas de apoyo para los rubros de Artes Escénicas, Artes Visuales, Artesanías, Audiovisual, Diseño, Editorial, Espacios Culturales, Música y Videojuegos (Ministerio de Cultura Provincia de Santa $\mathrm{Fe}, 2020)$. Asimismo, en mayo de 2020, este organismo ya había realizado el primer concierto en vivo y sin público, bajo modalidad virtual.

A nivel local municipal, la demanda de conocimiento del propio sector había sido enunciada, solicitada y proclamada en varias oportunidades, como modo de conocer el "termómetro de la cultura en Rosario" (Foro de Producción Artística y Social de la Cultura, 2017) a fin de recabar información sustantiva para las futuras acciones (relevamientos sectoriales que vinieron de la mano de los propios protagonistas en clave autogestival.

A este reclamo, se sumó la percepción en términos de "lentitud" por parte de la cartera cultural para reaccionar a las críticas condiciones del sector frente al Covid-19. Esto puso en evidencia la ausencia de una política general para la esfera cultural municipal y expresó la emergencia de nociones y prácticas contrastantes respecto del papel del Estado y del propio trabajo cultural. Desde nuestra perspectiva -y como resultado del análisis de registros de material de campo-, uno de los aspectos que opera como sustrato en las demandas y discusiones de la trama de las políticas culturales se vincula con ciertas concepciones acerca del trabajo cultural en términos de "no trabajo" o "gusto", algo que se corporiza de diversas maneras. De allí que, frente a la emergencia sanitaria y las restricciones producto de las medidas, las y los trabajadores culturales fueran "no esenciales" - respecto de las actividades permitidas más directamente relacionadas con el ámbito de la salud-, comprensible en un contexto de pandemia. Pero lo difícil de entender es por qué, luego de tres meses de instaladas las restricciones, no se abordaron las condiciones de precariedad y vulnerabilidad del sector la 100 días de interrumpidas las actividades artísticas-cultu- 
rales locales). Estas características, padecidas por trabajadoras y trabajadores culturales, se observan tanto en las propias dependencias culturales - falta de recursos, infraestructura, entre otros-, como en sectores artístico-culturales de la ciudad, donde suelen generarse entrecruces de pertenencias desde "dentro" y "fuera" del Estado. Estas consideraciones en torno al trabajo cultural más general funcionaron como agravantes de la intemperie en la que quedó el sector independiente y autogestivo frente a la emergencia suscitada por la pandemia. Y que, como veremos en la secuencia de publicaciones locales, con el correr de los meses aumentó la conflictividad, expresada desde agrupaciones y organizaciones de distintos campos artísticos de la ciudad y desde los agentes estatales.

\subsection{Asunción de autoridades y discursos de la nueva gestión: el orden, el control y el respeto}

En 2019 el cambio de gobierno en Rosario se expresó en el protagonismo de la fracción radical ${ }^{11}$ que integró la coalición política del gobierno socialista, resultando intendente un líder del Partido Radical ${ }^{\mathbf{1 2}}$. Tras la asunción de nuevas autoridades de todo el gabinete en diciembre de 2019 , se anunció la primera actividad impulsada desde el municipio bajo el título "el verano del respeto": "volver a ser buenos vecinos. Volver a ponernos el casco. Tirar la basura en su lugar. No invadir la senda peatonal. Es disfrutar pero respetar el descanso del otro (...) volver a una Rosario de la que estemos orgullosos, de la que se hable bien en todo el país" (Rosario Noticias, 2020).

En marzo de 2020 y en circunstancias de la apertura de las Sesiones del Consejo Deliberante, el Intendente inauguró el año con las siguientes palabras:

Empezar a ordenar la ciudad no es solamente administrar una crisis. Ordenar es estar, controlar, actuar. Y, sin dudas, ordenar es respetar". Por este motivo, el intendente anunció que se integrarán y se unificarán los organismos de control en una única agencia (Rosario Noticias, 2020).

El discurso del "control", el "orden" y el "respeto", fue impulsado por las nuevas autoridades en el poder, vinculado a los altos índices de violencia y muertes registradas en la ciudad en las últimas décadas y con un claro énfasis en las políticas de seguridad.

La retórica del respeto impregnó las actividades culturales masivas del área cultural durante los primeros meses de mandato. Y según palabras de la nueva funcionaria del área, procedente del campo de la educación a cargo de la Secretaría (Intendencia Municipal de Rosario, 2019), la directriz de la gestión era expresada en términos de: "convertir a Rosario en la ciudad del respeto, de la solidaridad y la convivencia" (Rosario 3, 2019). Ese sello se trasladó a la esfera cultural sin una política orgánica y específica para el sector, en un contexto en el cual ya se percibía una disminución de los recursos del área ${ }^{13}$.

\subsection{Medidas en pandemia y conflictividad local}

El inicio de las actividades culturales luego del triunfo eleccionario se hacía eco de lo propugnado desde la Intendencia con la retórica del respeto y el control. Un énfasis que ponía en evidencia el acento de la gestión de gobierno en la regulación y los controles urbanos ${ }^{14}$. Según lo registrado por parte de personal de algunas áreas, el cambio de rumbo en relación a los acentos de la gestión de gobierno se venía gestando en el devenir de las alianzas de la coalición política.

En la ciudad de Rosario, las medidas de aislamiento provocaron el cierre de numerosos espacios culturales, dependencias administrativas y de exposición. En medio de los cambios de rumbo de las políticas públicas producto de los resultados eleccionarios del 2019 y las medidas provocadas por la pandemia en 2020: ¿en qué situación se encontró el campo cultural público en Rosario y Santa Fe? El parte registrado en el sector cultural anunciado y denunciado a través de distintos medios de comunicación y redes sociales, era una realidad no escuchada desde antes de la crisis mundial generalizada recrudecida por la pandemia. Los alertas del sector se hicieron visibles a partir de reclamos específicos procedentes de distintos espacios y organizaciones de las artes plásticas, el teatro, la música, las artesanías, los centros culturales independientes y técnicos de eventos, por nombrar algunos. Tal como refiere un manifiesto elevado por diversos grupos artísticos y culturales de la ciudad, 
luego de 100 días de implementación de las medidas sociosanitarias que impedía el desarrollo de la actividad laboral del sector, la situación se había "tornado desesperante" para las y los trabajadores de la cultura, que hacían pública la ausencia de escucha por parte de las autoridades, falta de pagos a las y los artistas que habían sido contratados por el área en el año anterior (presupuesto importante asignado al área ${ }^{15}$ pero sub ejecutado por parte de la cartera cultural) (Redacción Rosario, 2020).

En esa misma dirección, otro comunicado insistía en el reclamo hacia la Intendencia y, en específico, a la Secretaría de Cultura y Educación. En ese texto, se reiteraba el estado de movilización y demanda de algún tipo de ayuda económica, frente a la prohibición de trabajar debido a las medidas sociosanitarias, una decisión que según indicaron se tomó "sin contemplar cómo vamos a sobrevivir"(El Ciudadano y la Región, 2020). El escrito aludía al llamamiento a distintas dependencias estatales a las cuales habían sido derivados desde el área cultural, tales como el Ministerio de Desarrollo Social de Santa Fe, de ahí al Ministerio de Trabajo y Seguridad Social, sin obtener respuestas hasta ese momento, cuando se contaban 110 días de interrupción de la actividad (El Ciudadano y la Región, 2020).

Luego de reuniones entre agrupaciones y autoridades, se implementaron medidas puntuales tales como la entrega de bolsones con alimentos y líneas de subsidios para distintas ramas de la actividad. Y, simultáneamente, ciertas noticias exponían que los presupuestos destinados al área cultural estaban siendo recortados ${ }^{16}$, aludiendo: denuncias de subejecución, interrupción de obras que habían sido iniciadas en la gestión anterior ${ }^{17}$ y renuncias de directores y coordinadores de distintas dependencias. Entre las razones de las desvinculaciones de los cargos se mencionaban: escasez de asignación presupuestaria luego de la pandemia, disminución de recursos -ya asignados en el ejercicio 2019-. ajuste presupuestario en el área de cultura, insuficiencia de las respuestas del municipio al sector (Rosario 12, 2020).

En este escenario, ¿cómo dar crédito al discurso del "respeto" si las condiciones materiales necesarias para el desarrollo de las labores de las áreas estatales y los derechos de los grupos de artistas y productores culturales no estaban garantizados? En este sentido, la Ley 27.467 de emergencia sanitaria y el Decreto 457 a nivel nacional (Boletín Oficial de la República Argentina, 2020) planteaban medidas de distinto orden tendientes a afrontar la pandemia, entre las cuales los fondos presupuestales debían ser redirigidos hacia las áreas de salud en todos los ámbitos jurisdiccionales del país (resolución que constituye un elemento importante en la consideración del estado de situación de los recursos asignados frente a la pandemial. Al mismo tiempo, dado que las y los trabajadores culturales no eran ni son considerados "esenciales" dentro de las disposiciones impuestas por el contexto de pandemia, esta lateralidad respecto de la especificidad de la labor se sumó a la crítica situación de los sectores culturales independientes de la ciudad. Sin negar la importancia que tales medidas representan en términos sanitarios y el papel de las y los llamados trabajadores esenciales en cuanto a sus tareas en la atención, contención y cuidados respecto del virus, la situación del sector seguía agravándose y deteriorándose.

Hacia fines del año 2020, y mientras aumentaban las tensiones en el ámbito cultural, la atención de las autoridades se centró en la confección de protocolos que garanticen el regreso de actividades bajo las condiciones sanitarias requeridas en las disposiciones generales, debates acerca del regreso a la presencialidad en los distintos espacios, apertura de salas, centros culturales y museos, además de espectáculos, actuaciones, presentaciones al aire libre, la realización de clases y toda la variedad de tareas que componen la actividad del sector cultural. Según la autoridad del área cultural: "para que la actividad productiva cultural comience. Porque entendemos que la cultura no es solamente un entretenimiento, sino que es una actividad productiva de la cual vive mucha gente, y actores, actrices, bailarines, músicos..." (Funcionaria en Santone, 2020).

La apertura del techo de un importante teatro y la preparación de los museos para la futura visita de público, fueron agregándose - no sin contradicciones- a las actividades para y del sector cultural. $Y$ en el mes de diciembre se observó cierta flexibilización de las medidas asociadas al DISPO en el marco de fuertes presiones de distintos sectores: extensión de los horarios de apertura y de cierre de comercios y bares y ampliación de actividades exceptuadas. Pero las medidas no fueron sólo la respuesta a las presiones. El sector cultural ya ex- 
perimentaba un retraimiento económico durante el 2019 y los anuncios de inicio de la apertura de espacios, elaboración de protocolos, pruebas piloto de eventos y líneas de fomento eran impostergables para la supervivencia de artistas, productores y gestores culturales, con o sin pandemia.

Las tensiones evidenciadas en las dependencias culturales estatales no sólo se hicieron visibles en las repercusiones de manifiestos, concentraciones y marchas frente al municipio; en el mes de febrero de 2021, una escalada de publicaciones y expresiones en las redes sociales, desembocó en la renuncia de la máxima funcionaria a cargo del área de cultura. En su lugar asumió un actor del campo artístico local con una vasta trayectoria en la gestión de diversas acciones y espacios culturales estatales (Intendencia Municipal de Rosario, 2021).

Mientras el sucesor en el cargo asumía la tarea, expresaba: "vamos a hacer una gestión de posguerra" (4 de febrero de 2021. Rosario 3) y se posicionó desde el inicio en la condición crítica del área. Aquí vislumbramos un contorno a este corto período diciembre 2019 a febrero 2021- donde lo cultural parece haberse desdibujado en acciones aisladas sin una mirada que congregue sólidamente a los diversos y complejos sectores que conforman el campo cultural de la ciudad. El cambio de figura al frente de la cartera cultural parece retomar la tradición de las gestiones anteriores, al convocar a un artista reconocido de la ciudad que es parte de la planta de trabajadores y trabajadoras estatales (El Ciudadano y la Región, 2021).

Pasados unos meses del cambio de autoridad en cultura municipal, la controversia acerca de la capacidad de maniobra - sin presupuesto ${ }^{18}$ - no parece encontrar solución. $Y$ en una entrevista a un medio de comunicación local que aludía a la escalada de conflictos que se siguen suscitando en el sector, la autoridad de la cartera hizo alusión a las polémicas sobre las imposibilidades del área para dar solución a los reclamos de distintas agrupaciones, al comparar el presupuesto en cultura con una "milanesa" (Radio Sí, 2021). En alusión al magro presupuesto del área cultural producto de la reorientación de fondos hacia Salud por las medidas de emergencia, el secretario expresaba: "Lo que hacemos con el pedazo de milanesa que nos queda es tratar de repartirlo lo mejor posible" (Bulsicco, 2021).

\section{Consideraciones finales}

Para responder a las interrogantes iniciales, repasamos algunos momentos claves de las políticas culturales públicas de la ciudad de Rosario a través de cambios en su institucionalidad normativa, representaciones y prácticas respecto a la cultura, el trabajo y el Estado que articulan las principales transformaciones del sector cultural (Cardini, 2020). Las modificaciones en la composición del gobierno a nivel municipal y las condiciones provocadas por la pandemia Covid-19 confluyen en un nuevo punto de inflexión para las políticas culturales que es preciso leer en términos de continuidades, rupturas y/o profundización de los procesos ya presentes en la configuración del campo cultural de la ciudad.

Las disputas actuales por los sentidos acerca de lo político, la cultura y el trabajo, por parte de distintos/as agentes del campo cultural puede esquematizarse, por un lado, respecto a la histórica apelación de Rosario como "ciudad de la creación" en la planificación estratégica (PER, 1998) y como cualidad-capacidad de sectores, espacios y agrupaciones artístico-culturales de la ciudad. Y por otro, respecto de los lineamientos recientes que exaltan la retórica del orden, el control y el respeto como corsé normativo (y luego sanitario) de las políticas de gobierno recientes antes y durante la pandemia.

El itinerario de las gestiones culturales locales desde la apertura democrática en adelante con variaciones, se caracteriza por su apuesta al reconocimiento de la labor cultural, creativa y artística que hace a la identidad de la ciudad. Así, el cambio en la autoridad máxima del área cultural - por su trayectoria- podría estar en sintonía con el reconocimiento de las experiencias acumuladas de las gestiones de la cartera; además de contener en potencia la posibilidad de encauzar los conflictos hacia "adentro" y hacia/con el "afuera" del Estado. Pero, estas afirmaciones resultan cuestionables frente a la profundización de las desigualdades en las condiciones de vida del sector cultural caracterizado por la precariedad en sus relaciones contractuales y situaciones laborales de las últimas décadas, agravadas y evidenciadas por la pandemia Covid-19. 
El dominio público que adquirieron los sucesos que enumeramos, se convirtieron en oportunidades para observar el escenario adverso, contradictorio y desigual de las políticas culturales en un contexto específico bajo el cimbronazo de la pandemia, que desembocó en el colapso de la gestión cultural y devino en el primer cambio en el gabinete municipal. Y esto también está ligado a las sospechas del deslizamiento hacia medidas tendientes a incorporar la dinámica empresarial en la configuración de las políticas culturales de la ciudad. Lo que está en el centro de estos debates es una concepción del Estado neoliberal que reduce las políticas en cultura a través del recorte en el área, la disminución de actividades libres y gratuitas en espacios emblemáticos de actuación, cierre de programas y proyectos de larga data, y redirige cada vez más su atención hacia los sectores empresariales de la ciudad.

¿Las políticas y las instituciones -en este caso en cultura- son capaces de liderar, acompañar o impulsar procesos de transformación y cambio social? Si pensamos que los agentes de las políticas involucran a toda una trama de sujetos, organizaciones y agentes podemos responder que sí, dado que fueron precisamente integrantes del propio plantel burocrático quienes denunciaron públicamente las condiciones de desfinanciamiento del área, y/o los propios colectivos artístico-culturales quienes reclamaron abiertamente medidas para la subsistencia del sector cultural de la ciudad. Si nos ubicamos en la posición del gobierno actual, bajo la figura de las autoridades a cargo del área cultural, la respuesta se torna ambigua, con el colapso de esa gestión cultural que devino en el primer cambio en el gabinete municipal y un nuevo referente que asume el área como "campo de batalla".

Los desafíos actuales sobre el Estado, las políticas públicas y la cultura pueden formularse a través de las siguientes preguntas: ¿serán las políticas, las instituciones y los diversos agentes culturales capaces de atravesar indemnes las transformaciones ocasionadas por la pandemia? ¿Cuán respetuosas podrán ser las acciones y políticas futuras para y con el sector cultural con escasos recursos económicos producto de los redireccionamientos por la emergencia sanitaria? ¿Cómo quedarán configuradas las políticas culturales del municipio en el contexto de tratamiento de las políticas de seguridad y "control"? ¿Tendrá la cultura como esfera de las políticas públicas un papel "esencial" destacado en la construcción de una sociedad menos violenta, desigual y post-pandémica? Con estas preguntas llegamos a otro punto de partida para analizar los desafíos actuales y futuros de las políticas culturales contemporáneas en América del Sur.

\section{Notas}

1. Con el gobierno nacional al frente de la Alianza Cambiemos, en 2019 se realizaron elecciones generales que modificaron la composición de las autoridades en todos los niveles jurisdiccionales del contexto aludido: presidencia, gobernación de la provincia de Santa Fe e intendencia de la ciudad. Los resultados eleccionarios dieron como ganadores a referentes del peronismo a nivel presidencial y provincial, y al radicalismo en su alianza junto a diversos sectores políticos en la intendencia de Rosario.

2. El relevamiento de documentos periodísticos nos condujo a rastrear los episodios seleccionados a través de prensa local: Diario La Capital, El Ciudadano y la Región, Suplemento Rosario 12 del Periódico Página 12, periódicos en línea: Redacción Rosario, Rosario Express, Rosario Noticias, Rosario 3 y radios de la ciudad como LT3, LT8 y Radio Sí.

3. Desde el 20 de marzo de 2020 hasta octubre del 2021, en los ámbitos de trabajo en los cuales nos desempeñamos como investigadoras y docentes, se implementó “la estricta y prioritaria prestación de servicios mediante la modalidad de trabajo remoto (...) para las y los agentes de todas las jurisdicciones, organismos y entidades del Sector Público Nacional (Boletín Oficial, 2021).

4. En este artículo retomo parte de la argumentación desplegada en otros escritos (Cardini, 2021). Agradezco a la Revista y sus editoras/es por la oportunidad de complejizar las reflexiones producto de las observaciones de las y los dictaminadores.

5. En estos pasajes recuperamos referencias teórico metodológicas que hemos mencionado en otros artículos (Cardini, 2020).

6. Retomamos parte de los aportes del debate comunicación/cultura y la caracterización de las notas periodísticas en tanto poseen una estructura abierta, implican una manera de escribir marcada por la exterioridad de la periodicidad y un modo de lectura que rompe la distancia del escritor al situarlo en el espacio de una interpelación permanente con los lectores (Martín-Barbero, 1987). 
7. Con distancias en tiempos, contextos y perspectivas, seguimos algunos de los postulados de la propuesta de Sunkel (1987) -quien trabajó en el espacio de la prensa masiva en Chile buscando comprender los modos de representación de lo popularpara abordar lo cultural a partir de acontecimientos puntuales de las políticas culturales en el contexto rosarino desde diciembre de 2019 a febrero de 2021 (vía fructífera para el tratamiento del material periodístico locall. Del corpus total de notas relevadas hasta el momento, hemos utilizado las que comprenden los acontecimientos mencionados en la introducción.

8. Con variaciones según los mandatos específicos, desde 1989 el gobierno municipal estuvo al frente del Partido Socialista Popular.

9. En otros trabajos profundizamos en las trayectorias políticas y militantes de las y los funcionarios y trabajadores de áreas estatales (Cardini, 2018, 2020).

10. Durante la primera década del siglo XXI, más específicamente en 2007, también la composición política al frente del gobierno municipal, en coalición con otros sectores políticos, se irradió a nivel provincial. En materia de cultura ese período planteó diversas acciones inéditas como la creación del primer Ministerio de Innovación y Cultura del país.

11. La Unión Cívica Radical fue fundada en 1891 por Leandro N. Alem.

12. El Frente Progresista Cívico y Social (FPC y S) es una coalición política entre el Partido Socialista, el Partido Radical y Generación para un Encuentro Nacional (GEN) que en 2019 ganó las elecciones municipales al frente del radical Pablo Javkin.

13. Según información proporcionada por trabajadores/ as de áreas, la disminución de los recursos limitó cantidad y frecuencia de las actividades programadas durante el 2019; algo que se empezó a percibir en los meses posteriores a las elecciones del mes de agosto de 2019 y hasta la asunción de las nuevas autoridades de gobierno en diciembre de 2019 y los inicios del 2020 hasta el comienzo de la pandemia.
14. Con anterioridad a los resultados eleccionarios del 2019, la fracción política que asume el gobierno municipal, remitía la existencia de una sobredimensión del área cultural, en contraste con el menor número en la composición de la agencia de control y convivencia -para mayor información consultar página institucional del municipio-.

15. El municipio de Rosario tiene una política de transparencia institucional, que implica la publicación del proyecto de presupuesto anual por finalidad. Si observamos la secuencia de presupuestos proyectados del 2019 al 2021, en el ítem Promoción Cultural y Educativa, el porcentaje asignado se mantiene: $5,3 \%, 5,1 \%$ y 5,1 . Por motivos de espacio hemos recortado la información correspondiente al período seleccionado.

16. Los ajustes económicos al interior de las dependencias estatales en cultura se expresaron en la falta de acceso a recursos mínimos para el funcionamiento cotidiano de las actividades (papel, tinta para imprimir, acceso a conectividad, por nombrar algunos insumos), y el retroceso en las asignaciones previamente convenidas para la realización de distintas labores proyectadas y acordadas. En otras situaciones, la no asignación de indicaciones y/o tareas para el personal era percibido como un proceso de vaciamiento de programas e instituciones.

17. Un ejemplo en esta línea es lo sucedido con el proyecto de ampliación de un importante museo, obra que respondía a un acuerdo de las gestiones provincial y municipal previas y que pese a encontrarse en su etapa inicial - con la extracción de añosos árboles y la excavación del predio- en enero de 2020 fue interrumpida por el gobierno actual.

18. Esta expresión podría resultar infundada si seguimos la progresión de los presupuestos que mencionamos en parágrafos anteriores, pero las declaraciones de las autoridades y los relatos de trabajadores/as de las dependencias expresaban de distintas maneras la disminución significativa de los recursos del área.

\section{Referencias}

Achilli, E. (1998). Vivir en la pobreza urbana. El derecho a una interculturalidad no excluyente. Revista Lote, No 18. http://www.fernandopeirone.com.ar/Lote/nro018/achilli.htm.

Bayardo, R. (2008). Políticas culturales: derroteros y perspectivas contemporáneas. RIPS. Revista de Investigaciones Políticas y Sociológicas, 7 (1), 17-29.

Boletín Oficial de la República Argentina. (2021). Decisión Administrativa 280. Modalidad de trabajo remoto. http://www.boletinoficial.gob.ar/ 
Boletín Oficial de la República Argentina. (2020). Decreto Nacional 457. Decreto de Necesidad y Urgencia que Modifica el Presupuesto General de la Administración Nacional para el Ejercicio 2020. http://www.boletinoficial.gob.ar/

Bulsicco, A. (6 de julio de 2021). Emergencia Cultural en Rosario: Programa “Nadie es perfecto”. [Transmisión de radio]. Radio Sí. Recuperado de https://ar.radiocut.fm/audiocut/ dante-taparelli-sobre-emergencia-cultural/

Cardini, L. (2021). Entre creación y respeto: lineamientos de la gestión cultural en las políticas públicas recientes de la ciudad de Rosario, Santa Fe. Ponencia presentada en el 12 CAAS. La Plata, Argentina.

Cardini, L. (2020). Itinerarios de las políticas culturales públicas en la ciudad de Rosario, Argentina. Desacatos 63. Revista de Ciencias Sociales, pp. 70-85.

Cardini, L. (2018). Lo cultural en la planificación estratégica de la ciudad de Rosario. Actas del CEACU. Rosario: FH y A., UNR.

Cerdeira, M. \& Lacarrieu M. (2016). Formación y profesionalización de agentes culturales en América Latina. Experiencia del Instituto de Cultura Pública del Ministerio de Cultura de la Nación (2013-2015). XII ENECULT, Encontro de Estudos Multidisciplinares em Cultura.

Crespo, C., Morel, H., \& Ondelj, M. (Comp.). (2015). La política cultural en debate: diversidad, performance y patrimonio cultural. Ediciones CICCUS.

Elía, C. (2009). La formación profesional para la gestión y administración en el sector de la cultura argentina. Revista Aportes para el Estado y la Administración Gubernamental, Edición, 23, 107-118.

El Ciudadano y la Región. (2020, 1 de julio). Sectores en crisis. Artistas, músicos, artesanos y trabajadores de la cultura piden reunión con Javkin. https://www.elciudadanoweb. com/artistas-musicos-artesanos-y-trabajadores-de-la-cultura-piden-reunion-conjavkin/

El Ciudadano y la Región. (2021, 4 de febrero). Primer cambio de la gestión Javkin. https://www. elciudadanoweb.com/el-reconocido-artista-dante-taparelli-es-el-nuevo-secretario-de-cultura-de-rosario/

Fondo Nacional de las Artes. (1964). Artes y letras argentinas, Año VI. Buenos Aires.

Foro de Producción Artística y Social de la Cultura. (2017). Secretaría de Cultura y Educación, Municipalidad de Rosario.

García Canclini, N. (Ed.). (1987). Políticas Culturales en América Latina. Editorial Grijalbo.

Getino, 0. (1995). Políticas públicas y legislación. En Las políticas culturales en la Argentina. (pp. 339- 352). Ediciones Colihue.

Intendencia Municipal de Rosario. (2019). Decreto Municipal 2404. Secretaria de Cultura y Educación. Designación. https://www.rosario.gob.ar/normativa/ verArchivo?tipo=pdf\&id=156611

Intendencia Municipal de Rosario. (2021). Decreto Municipal 157. Secretario de Cultura y Educación. Designación. Boletín Oficial Electrónico No 1166. https://www.rosario.gob.ar/ normativa/

Landi, 0. (1987). “Campo cultural y democratización en Argentina”. En García Canclini, N. (Ed.) Políticas Culturales en América Latina. (pp. 145-173). Editorial Grijalbo.

La Tribuna (1978, 5 de junio). Arte popular argentino en la Estación Fluvial. Rosario. Archivo del Museo de la Ciudad de Rosario, Secretaría de Cultura y Educación, Municipalidad de Rosario.

Martín-Barbero, J. (1989). Procesos de comunicación y matrices de cultura. Itinerario para salir de la razón dualista. Ediciones Gili, S.A.

Ministerio de Cultura. (2020). Medidas para el sector de la cultura ante el COVID-19. Argentina. Consultado el 20/11/2020 de: https://www.cultura.gob.ar/medidas-en-el-sectorcultural-ante-el-covid-19-8932/

Ministerio de Cultura Provincia de Santa Fe. (2020). Plan de Fomento. Argentina. Consultado el 24-11-2020 de: https://www.santafe.gov.ar/index.php/web/content/view/full/235842

Municipalidad de Rosario. (2018). Listado de personal. Secretaría de Cultura y Educación. Septiembre 2018. Consultado el 12-10-2018 de: http://www.rosario.gob.ar/web/.

País, M. (2016). “Políticas y Gestión cultural pública en Argentina. Apuntes teóricos-metodológicos para su investigación/intervención”. En M. Rotman (Comp.). Dinámicas del poder. Procesos patrimoniales, políticas y gestión de la Cultura (pp. 243-275). Editorial FFyL.

Plan Rector Rosario (PER). (1998). Programa de “Autonomía local, modernización y descentralización municipal”. Argentina. https://www.rosario.gob.ar/web/sites/default/files/ per_1998.pdf 
Raggio, L. (2015). “Los Derechos Culturales. Estado, medios de comunicación y organizaciones de la sociedad civil". En M. Rotman (Comp.), Dinámicas de poder. Procesos patrimoniales, políticas y gestión de la cultura (pp. 211-241). Editorial FILO, UBA.

Redacción Rosario. (2020, 26 de junio). Reclamo sin respuesta. Los artesanos autoconvocados vuelven a movilizarse. https://redaccionrosario.com/2020/06/26/los-artesanosautoconvocados-vuelven-a-movilizarse/

Redacción Rosario. (2020, 1 de junio). Los espacios culturales se declaran en emergencia. Redacción Rosario. https://redaccionrosario.com/2020/06/01/los-espacios-culturalesculturales-se-declaran-en-emergencia/

Renuncia masiva de directores de cultura municipal. (2020, 3 de diciembre). Como autor Rosario Express. https://rosarioexpress.com.ar/interior/866

Rosario Noticias. (2020, 3 de enero). Una ciudad mejor, entre todos: la Municipalidad lanzó la campaña «El verano del respeto». https://www.rosarionoticias.gob.ar/page/noticias/id/239366/title/Una-ciudad-mejor\%2C-entre-todos\%3A-la-Municipalidadlanz\%C3\%B3-la-campa\%C3\%B1a-\%C2\%ABEl-verano-del-respeto\%C2\%BB

Rosario Noticias. (2021, 4 de marzo). Apertura de las Sesiones del Consejo Deliberante de Rosario. https://www.rosarionoticias.gob.ar/page/noticias/id/250335/title/Javkin:$\%$ C2\%ABVamos-a-unificar-los-organismos-de-control\%C2\%BB

Rosario 12. (2020, 4 de diciembre) Renuncias en direcciones generales de Cultura municipal. No quieren seguir en la gestión Página 12, Suplemento Rosario 12. https://www.pagina12.com.ar/309801-no-quieren-seguir-en-la-gestion

Rosario 3. (2019, 11 de noviembre) La próxima secretaria de Cultura defendió a Scalona: "Es un gran profesional y persona". https://www.rosario3.com/informaciongeneral/La-proxima-secretaria-de-Cultura-defendio-a-Scalona-Es-un-gran-profesional-y-persona--20191111-0047.html

Rosario 3. (2021, 4 de febrero). Vamos a hacer una gestión de posguerra. https://www.rosario3. $\mathrm{com} /$ politica/Dante-Taparelli-nuevo-secretario-de-Cultura-Vamos-a-hacer-unagestion-de-posguerra-20210204-0012.html

Santone, G. (2020, 18 de noviembre). Apertura del techo corredizo en el Teatro La Comedia, en la reapertura de los espacios: Programa "Una tarde perfecta" [Transmisión de radio]. LT8. Recuperado de: https://ar.radiocut.fm/audiocut/carina-cabo-secretaria-cultura-rosario/\#

Sistema de Información Cultural de Argentina (SInCa). (2020). ASPO \& Cultura. https:// www.sinca.gob.ar/VerNoticia.aspx? ld =58

Sunkel, G. (1987). “La representación del pueblo en los diarios de masas. Diálogos de la Comunicación, 17. Lima.

- Sobre la autora:

Laura Cardini es Licenciada en Antropología y Doctora en Humanidades y Artes por la Universidad Nacional de Rosario (UNR). Investigadora Adjunta del Consejo Nacional de Investigaciones Científicas y Técnicas (CONICET). Profesora Titular, Escuela de Antropología, Facultad de Humanidades y Artes, UNR.

\section{- ¿Cómo citar?}

Cardini, L. (2021). Políticas culturales disputadas: tensiones y desafíos de la cultura en contexto pandémico en Rosario, Argentina. Comunicación y Medios, (44), 130-141. https:// doi.org/10.5354/0719-1529.2021.61251 